\title{
El pasado en discordia. Miguel Antonio Caro y José María Quijano, 1872
}

\section{The Past in Discord. Miguel Antonio Caro and José María Quijano, 1872}

\author{
Patricia Cardona Z. ${ }^{1}$ \\ Universidad EAFIT (Colombia)
}

Recibido: 25-01-17

Aprobado: 20-03-17

\section{Resumen}

Este artículo analiza la polémica sobre la celebración del 20 de Julio como fiesta nacional de la Independencia de Colombia. Aquella dilucida asuntos relacionados con la historia patria, las interpretaciones del pasado, las pugnas ideológicas presentes en la selección de los acontecimientos y en la narración. Su busca mostrar cómo en la década de 1870 la historia patria era un saber vivo y central en la formación de la ciudadanía y de la República.

Palabras-clave: Historia patria, historiografía, retórica, interpretación.

\begin{abstract}
This article discusses the controversy over the celebration of July 20 as a national festival of the independence of Colombia. That controversy elucidates issues related to homeland history, interpretations of the past, the ideological struggles in the selection of events and narration. We are looking for showing how in the 1870's the homeland history was a lively and central knowledge in the formation of citizenship and of the Republic.
\end{abstract}

Key-words: Homeland history, historiography, rethoric, interpretation.

\footnotetext{
${ }^{1}$ (azuluaga@eafit.edu.co). Doctora en Historia, Universidad de los Andes. Profesora titular Departamento de Humanidades, Universidad EAFIT. Grupo de Investigación en Filosofía, Hermenéutica y Narrativas de la misma institución. Artículo producto de la investigación "La polémica por la Independencia: José María Quijano Otero y Miguel Antonio Caro", con el apoyo de la Universidad EAFIT. Autora de: La nación de papel (Medellín, Fondo Editorial Universidad Eafit, 2008) Y la historia se hizo libro (Medellin, Fondo Editorial Universidad Eafit, 2014), Trincheras de tinta (Medellín, Fondo Editorial Universidad Eafit, 2016).
} 


\section{A modo de introducción. Historia patria para venerar y emocionar}

Tienden a confundirse historia republicana e historia patria. Ambos vocablos corresponden a modos de concebir la historia y presentarla a sus posibles lectores y usuarios. La historia republicana se ocupaba de la fundación del Estado republicano, de las instituciones que lo detentan y de su exaltación, hecha por testigos presenciales y con la inclusión de documentos que probaban los hechos. El uso de un lenguaje elevado, la extensión de los textos, la publicación en grandes volúmenes y en varios tomos, hicieron de la historia republicana un saber dirigido a doctos y letrados. Según las convenciones historiográficas de la época, la historia se narraba como un relato épico de grandes hombres, grandes acciones y grandes obras. La guerra era el eje que vertebraba la narración; así se evitaba la dispersión en un sinnúmero de anécdotas que podían desviar el foco de interés, a la par que se exaltaba la actitud heroica como agente transformador de la sociedad ${ }^{2}$.

Por su parte, por historia patria entendemos un saber destinado fundamentalmente a promover el sentimiento por los héroes y los hechos que fundaron la patria, un discurso profundamente emotivo, memorioso y narrativamente simplificado y didactizado, siguiendo las condiciones de sencillez, secuencialidad e inteligibilidad que comprendía la retórica. Los textos se titularon compendios, epitomes, prontuarios o lecciones. Los escritores asumían la tarea del copista, que seleccionaba los datos y los organizaba de forma didáctica, más que la de investigadores que buscaban documentos para incluir hechos inéditos.

Más allá de considerarse un saber objetivo, sometido a procedimientos de control de las interpretaciones, la historia a la que nos referimos y que podemos definir como historia patria, era un relato que, aunque apelaba a la comprobación y la verificación documental, estaba más del lado de la retórica ${ }^{3}$, un tipo de discurso que se definía como verdadero porque podía relatar con fidelidad los hechos del pasado. Apenas se constituía en un saber objetivo,

${ }^{2}$ La retórica dividía las narraciones en historia ficticia, en la que los hechos referidos eran fingidos por el autor, y la historia verdadera, responsable de narrar fielmente lo sucedido en tiempos pretéritos; podía servir de pasatiempo, pero también debía ser útil: "es menester que el pasado nos instruya para el porvenir". El historiador debía mantener un tono elegante y comedido, evitando expresiones vulgares o humorísticas. Véase José M. Gómez Hermosilla, Arte de hablar en prosa y en verso, tomo 2, Madrid, Imprenta real, 1826, pp. 57-87.

${ }^{3}$ En vez de seguir las discusiones posmodernas que confunde la disciplina histórica con un relato definido por tropos literarios, estudiamos, más bien, los modos de transición entre la historia magistra vitae y la historia disciplinar. Al respecto véase Roger Chartier, Cuatro preguntas a Hayden White, "Historia y Grafia", 3 (1994), pp. 231-246. La historia patria sirve como estudio de caso para pensar los modos de aprehender el pasado y destacar su utilidad. Más allá de su función propedéutica, fue vocera de las glorias del pasado de la república, y discurso cívico para la formación de patriotas y ciudadanos. Patricia Cardona Z., Memoria, palabra y acción. La historia patria un saber para el sentimiento, "Anuario Colombiano de Historia regional y de las fronteras", 21(2) (2016). Recuperado de http://revistas.uis.edu.co/index.php/anuariohistoria/article/view/5540

Araucaria. Revista Iberoamericana de Filosofía, Política y Humanidades, año 19, n 38. Segundo semestre de 2017 Pp. 445-466. ISSN 1575-6823 e-ISSN 2340-2199 doi: 10.12795/araucaria.2017.i38.20 
en una disciplina (y no solo en una narración) responsable de explicar y comprender el presente.

La historia patria no era una disciplina para la reflexión o la crítica; era un saber destinado a henchir de orgullo y sentimiento los corazones de los ciudadanos, edificado sobre una base épica que ayudara a elevar a leyenda los tiempos, los hombres y los acontecimientos que habían dado origen a la república.

Dicha historia se había refigurado mediante el relato de grandes héroes y gestas, y organizado, primordialmente, en preguntas y respuestas que se fijaban en la memoria sin alterar la forma de la lección. Sus contenidos secuenciados y organizados cronológicamente, en párrafos cortos, eran coherentes con la construcción de ideales políticos representados por los héroes, cuyas proezas deberían servir para modelar la conducta cívica de sus habitantes.

La historia patria ayudó en la implementación de una ritualística cívica ${ }^{4}$, cuyo propósito era venerar a los héroes y fundadores de la patria, cuando apenas se iniciaba el proceso de desacralización política y la conformación del Estado como referente supremo de autoridad.

La historia patria varió con el siglo, fechas y personajes se moldearon con las necesidades culturales que enfrentó el país en el siglo XIX y en parte del siglo XX. Lo que puede constatarse, por ejemplo, con el protagonismo que fue adquiriendo Simón Bolívar, hasta consolidarse hacia la década de los ochenta del siglo XIX como el máximo héroe de la república; con las tensiones alrededor de Antonio Nariño, que lo elevaron paulatinamente al panteón patrio; y la pérdida de figuración de Santander, que solo se reivindicó en su faceta de hombre de las leyes hacia los años veinte del siglo XX.

La historia patria consiguió perfilarse en Colombia hacia 1870, cuando aparecieron textos destinados a su enseñanza: compendios, prontuarios y catecismos, elaborados para ser leídos colectivamente. Se afianzaba una versión del pasado que buscaba hacer de cada habitante un devoto dispuesto a morir por la patria, una historia que hacía hincapié en los deberes de los ciudadanos, en el mantenimiento de la república y sus instituciones, antes que en sus derechos. Un discurso que empezaba a esbozar un saber histórico nacional, que establecía nexos fraternales diacrónica y sincrónicamente en varios frentes. Uno de ellos fue el de las conmemoraciones, que generaron diversos textos justificatorios, explicativos o descriptivos, y que movilizaron a la opinión pública en torno a ellas.

Aunque, en esa época, en el país la historia seguía ligada a la retórica, ya se anunciaban algunos aspectos de su forma moderna; por ejemplo, la incorporación, tanto en los textos como en las discusiones, de documentos que

${ }^{4}$ Sobre fiestas cívicas, véase Marcos González, Ceremoniales, fiestas y nación. Bogotá: un escenario de los estandartes muiscas al himno nacional, Bogotá, Intercultura, 2012.

Araucaria. Revista Iberoamericana de Filosofía, Política y Humanidades, año 19, n 38. Segundo semestre de 2017. Pp. 445-466. ISSN 1575-6823 e-ISSN 2340-2199 doi: 10.12795/araucaria.2017.i38.20 
refrendaban o contradecían las afirmaciones. Se imponía también la idea de que la historia debía narrar con fidelidad los sucesos públicos y políticos de los pueblos, esto es, la del paso de las historias como "relaciones hechas con arte" a la historia como un saber que se ocupaba de contar la marcha ascendente de las recién aparecidas repúblicas modernas, es decir, un saber acotado geográficamente y por métodos filológicos y exegéticos, donde la fidelidad de la narración empezaba a verse desplazada por la explicación/comprensión de los sucesos, así como por una serie de huellas tipográficas y de precisión documental que demostraban el trabajo y la objetividad del historiador, y no ya solo su pericia "artística"5.

Este artículo busca estudiar de qué manera ese saber particular e importante en el siglo XIX se configuró, cómo estructuró algunos de los hitos convertidos en piedra angular de nuestra identidad y cómo la historia patria era, ante todo, un saber coherente con las expectativas de un país que, con un rumbo incierto, veía en el pasado un anuncio del brillante porvenir. La exposición la desarrollamos de la siguiente manera: 1) a partir de la polémica por la validez de la celebración o no del 20 de julio, buscamos describir la importancia de la historia, su representación e incidencia en la vida social y política; 2) mostramos el modo en el que pudo haberse configurado una forma particular del saber histórico, que se denominó historia patria, un saber útil y "actual" en el siglo XIX, que circuló por medio de formas orales y escritas, y que tuvo, sobre todo, una función propedéutica y formadora del "carácter" patriótico de las generaciones republicanas; 3) proponemos algunos casos sobre las formas que permitieron la "actualización del pasado" y su consecuente relevancia para la sociedad.

\section{La conmemoración polémica del 20 de julio}

Festividades públicas hoy reconocidas, hacia 1870 aún no eran efemérides que congregaban al país en su conjunto. Ese fue precisamente el caso del 20 de julio, fecha en la que se dio el grito de independencia en Santafé de Bogotá que, paulatinamente, fue elevándose a fecha de celebración nacional, en detrimento de otros gritos de independencia ocurridos a lo largo y ancho del virreinato de la Nueva Granada entre 1810 y 1812.

No puede pensarse que la elevación del 20 de julio a fiesta nacional fuera intención premeditada de las élites andinas para imponerse sobre las del resto del país. Más bien puede interpretarse como la búsqueda de principios unificadores, entre ellos la historia, para menguar la dispersión política, las

\footnotetext{
${ }^{5}$ Krzystof Pomian, Sobre la historia, Madrid, Cátedra, 2007, p. 59.
} 
pugnas regionales y la fragmentación política que amenazaban a la república ${ }^{6}$ : los hechos ocurridos en la capital pasaron a ser referentes de unidad; para entonces, no se pensaba en el reconocimiento de la diferencia histórica, étnica o cultural, sino en la construcción de referentes que unificaran y representaran a todos los habitantes del país.

En un artículo publicado en el periódico El Mosaico en 1859 se referían al 20 de julio como "la gran semana de Bogotá". Aunque era una fecha significativa, su transcendencia probablemente quedaba restringida a la capital y cada región celebraba su propio grito de independencia. Según el artículo aludido, la celebración no fue "muy fecunda, pues parece que cada día los ánimos decaen más". El cronista nos informa que ese día hubo cañonazos, procesiones y misa, y subrayó el esfuerzo de los colegios capitalinos para "celebrar tan grande día de la manera que les ha sido posible": con lucidos discursos en prosa y en verso ${ }^{7}$.

\section{Los pasos de la centralidad narrativa de la celebración}

La relativa calma que se respiraba empezando la década de los setenta del siglo XIX, así como el deseo de conformar referentes comunes que unieran política y culturalmente a un país dividido en estados federales con grandes fueros, llevaron a Manuel Murillo Toro (1816-1880) a gestionar una historia patria común entre todos sus ciudadanos.

Un primer momento se dio en 1871, cuando el 20 de julio se celebró, “abriendo una exposición de productos nacionales y extranjeros". La exposición reunió a todos los estados soberanos para dar a conocer sus riquezas con las que "Dios ha enriquecido esta tierra, a la cual le reserva sin duda grandes destinos".

El segundo paso se dio en 1872, cuando se planeó, con el apoyo del presidente y la intervención de la Iglesia, una gran fiesta para conmemorar el 20 de julio en la capital de los entonces Estados Unidos de Colombia. En ese festejo, los estados soberanos participaron con carros alegóricos, arcos florales, banquetes y bailes, expresando un verdadero regocijo "nacional". En una crónica sobre lo vivido aquel día, José María Cordovez Moure (1835-1918) describió a las nueve señoritas, "descendientes de los mártires de la Patria", portando una cinta unida al Acta de Independencia, "símbolo de unión entre los nueve estados que formaban la federación"9.

\footnotetext{
${ }^{6}$ Cfr. Raúl Román Romero y Vanessa Niño de Villeros, El día de la Independencia de Colombia. La exclusión de los hechos históricos de la región caribe, 1821-1919, "Memorias”, 21 (2013). Recuperado de http://rcientificas.uninorte.edu.co/index.php/memorias/article/viewArticle/3860/5065\#n_2

7 José Joaquín Borda, La gran semana de Bogotá, “El Mosaico”, Trim. 3. o 30 (1859), p. 338

8 J. J. Borda, El gran día, “El Mosaico”, Trim. 2, 25 (1871), p. 185.

9 José María Cordovez Moure, El 20 de julio de 1872 [en Reminiscencias de Bogotá]. Recuperado de http://www.banrepcultural.org/blaavirtual/historia/remini/remini10.htm. Los Estados Unidos de 
El tercer paso fue la proclamación del 20 de julio como gran fiesta de la patria o aniversario de la patria, mediante la Ley 60 del 8 de mayo de 1873 del Congreso de la República. El 20 de julio se impuso sobre las fechas en que los estados soberanos celebraban sus propios gritos de independencia, lo que propició la centralidad de la narrativa histórica que, aunque integraba a todo el territorio, tuvo sus hitos más importantes en los hechos acaecidos en Santafé de Bogotá. Desde entonces, esa fecha fue proclamada como efeméride nacional.

\section{Quijano y Caro: los contendientes en torno a la celebración}

En este proceso, el conservador José María Quijano Otero (1832-1883) fue protagonista. Por más de quince años ocupó la cátedra de Historia Patria en la Universidad Nacional. Su reputación de "historiador" se respaldaba en su colección de documentos impresos y manuscritos, sus publicaciones alusivas a la historia de Colombia y su posición como director de la Biblioteca Nacional. Como parte de sus funciones al frente de la Biblioteca, hizo una indagación histórica sobre el Utis Posidetis (del latín "como poseéis de acuerdo al derecho, así poseeréis") y la definición de fronteras entre los Estados Unidos de Colombia y el entonces Imperio del Brasil, con base en los documentos que reposaban en esa institución ${ }^{10}$. Este recorrido cultural le garantizó una posición privilegiada en cuanto al conocimiento histórico y lo habilitó para hacer parte de la comisión responsable de organizar los festejos del 20 de julio de 1872.

Fue periodista y redactor de varios periódicos, entre ellos La América, cuyo primer número salió ese 20 de julio de 1872. Desde este periódico defendió su posición ideológica con respecto a la historia y su militancia en las filas del Partido Conservador; asimismo, defendió su punto de vista sobre la independencia de Cuba y promovió una militancia conservadora más civilista y democrática, en contravía del conservatismo ortodoxo y ultrarreligioso que defendía Miguel Antonio Caro.

Miguel Antonio Caro (1843-1909) fue una de las figuras más importantes de las últimas décadas del siglo XIX colombiano. Hijo de José Eusebio Caro (uno de los fundadores del Partido Conservador), fue filólogo, gramático, político, escritor, defensor a ultranza del legado español y de la religión católica como principio de unidad política y moral de la nación. Caro mantuvo una posición férrea contra el liberalismo, especialmente contra la educación laica, la

Colombia estaban conformados por nueve estados soberanos: Antioquia, Bolívar, Boyacá, Cauca, Cundinamarca, Magdalena, Panamá, Tolima y Santander.

10 José María Quijano Otero, Memoria histórica entre los Estados Unidos de Colombia i el Imperio del Brasil, Bogotá, Imprenta de Gaitán, 1869. Escribió, con el patrocinio del Gobierno, un libro de historia patria que se publicó por entregas en el periódico oficial de instrucción pública La Escuela Normal entre 1872 y 1874. En 1874 salió en formato de libro: José María Quijano Otero, Compendio de historia patria, Bogotá, Imprenta de Medardo Rivas, 1874. 
secularización de la sociedad y la influencia de los pensadores liberales franceses e ingleses, como Jeremias Bentham y Herbert Spencer. Su protagonismo se acentuó durante la década de los ochenta del siglo XIX, cuando dio inició a la denominada Regeneración, un talante político que reivindicaba la unidad y el fortalecimiento del Estado central en detrimento del federalismo y el poder de las regiones. Sus ideales políticos quedaron consignados en la Constitución de 1886, que rigió los destinos del país hasta 1991, y en la que se implementó un proyecto nacional fundado en la identidad católica y en el centralismo político. Fue presidente en el período 1892-1898.

La posición moderada de Quijano Otero se enfrentaba a las ideas ultraconservadoras de Miguel Antonio Caro, difundidas por El Tradicionista, órgano ideológico del llamado "Partido Católico" y tribuna política desde donde Caro combatía al liberalismo, la masonería, la secularización y la modernización política. La postura de Caro talvez se debía a que su visión de la historia seguía afincada a las nociones de orden y tradición, en las que comprendía la "hispanidad" como forma de plenitud política del país, en la que se intersectaban pasado, presente y futuro. La hispanidad puede concebirse como una forma utópica, un paraíso prometido en el que se fundían el cristianismo, el castellano y los valores hidalgos y caballerescos de los españoles venidos a América, para construir una sociedad contraria a los valores utilitarios y mercantiles del mundo anglosajón.

Así pues, una polémica por el 20 de julio, llevada a cabo en los periódicos dirigidos por Quijano y Caro, no era solo un problema de datación histórica: era una puesta en tensión de dos maneras de pensar el pasado, la patria y el porvenir, dos modos contrapuestos de concebir la fundación de la república y definir a sus protagonistas. También era una forma de trazar las interpretaciones del pasado y con ellas un modelo para pensar el porvenir: como revolución o decadencia, como ascenso o hecatombe.

La polémica hace explícitas las consideraciones de la época acerca de la verdad histórica, el papel del testigo y del historiador, las interpretaciones y sus usos políticos, la historia patria como un relato en pugna y las disputas ideológicas en juego. La polémica se publicó entre julio y agosto de 1872 . La parte central de la polémica está formada por seis artículos, tres de Caro (números 66, 67 y 68) y tres de Quijano (números 6, 8 y 10). Haciendo un rastreo, hemos encontrado otros tres o cuatro artículos que deben ser incluidos, ya que ayudan a entender qué se discutía y la complejidad de la discusión: uno del Diario de Cundinamarca, que fija las bases de la discusión (19 de julio de 1872). Tres de Caro: el primero, del 11 de julio, demeritaba el festejo del 20 de ese mes; el 23 de julio escribió otro haciendo un balance de la fiesta y remató con la hipótesis de que el 20 de julio no debía celebrarse la independencia; en el último, llamado "Historia novelesca o mentiras históricas", del 1. ' de agosto, 
desacredita la versión de la independencia del Diario de Cundinamarca. Además, está un artículo del 31 de julio, en el que Quijano Otero refutaba a Caro y que fue, finalmente, el que desató la polémica. En la parte que sigue del texto nos centramos en la polémica y aunque no la abordamos en su totalidad, pretendemos dejar una idea de lo que en ella se debatió.

\section{El artículo que desató la polémica}

Con ocasión de los anunciados festejos del 20 de julio, el Diario de Cundinamarca publicó el 19 de julio de 1872 un extenso artículo intitulado "Nuestra revolución", una apología de la independencia, en la que se remontaban sus antecedentes hasta el movimiento comunero de $1781 \mathrm{y}$ se extendía su benéfico influjo hasta el mismo año 1872. Este artículo fue escrito por Florentino Vezga (1832-1890), miembro de los círculos intelectuales del liberalismo radical, naturalista y el primer escritor ocupado en redactar columnas diarias para el Diario de Cundinamarca ${ }^{11}$. Vezga introdujo en el artículo en cuestión una visión evolutiva de la historia, en la que los hechos representaban un avance cultural y político de la sociedad, impulsado, principalmente, por la república y el conocimiento racional. La sociedad, en la perspectiva de Vezga, se dirigía hacia la prosperidad y era significativamente mejor la situación moral y política del país en 1872, de lo que había sido en el ocaso del mundo colonial.

El artículo subrayó no tanto la idea de independencia, cuanto la de revolución, para sostener que la de Estados Unidos de Colombia se había originado hacía noventa años y que gracias a ella el país había transitado por una senda de notables transformaciones, evidentes en la independencia, la soberanía, el gobierno democrático y federal. E1 20 de julio era, pues, el cenit de un proceso incubado en el alzamiento comunero en 1781, prueba de la "vocación para la libertad, la igualdad y la justicia", cuando la Ilustración era desconocida en el país, y "no se sabía qué era imprimir ni publicar un periódico [...] ni siquiera se había pensado en fundar una expedición botánica"12.

Según el artículo "Nuestra revolución", cuatro momentos habían sido precursores del 20 de julio, cuatro "revoluciones" que habían transformado a la sociedad y habían señalado el camino libertario a seguir. Se trata de cuatro hitos que todavía en la Historia Patria se encadenan de manera causal: el primero fue la revolución comunera de 1781 en el virreinato de la Nueva Granada, el cual solo buscaba mayores consideraciones por parte de las autoridades coloniales

${ }^{11}$ F. V. [Florentino Vezga], Nuestra revolución, “Diario de Cundinamarca”, Bogotá, año III, 774 (19 de julio de 1872), pp. 883-884.

12 Ibid., p. 883.

Araucaria. Revista Iberoamericana de Filosofia, Politica y Humanidades, año 19, n 38. Segundo semestre de 2017. Pp. 445-466. ISSN 1575-6823 e-ISSN 2340-2199 doi: 10.12795/araucaria.2017.i38.20 
en el pago de impuestos y no la independencia; su lema fue "Viva el rey, muera el mal gobierno"13. Según artículo mencionado el 16 de marzo de 1781, "se inició nuestra revolución y por eso hemos dicho que tiene 90 años"14.

Los Comuneros habrían inspirado 12 años después a los más influyentes letrados de Bogotá a "imprimir y circular en el seno de las familias el decálogo de la civilización moderna": los Derechos del Hombre. El segundo hito fue, pues, la traducción de estos derechos, por Antonio Nariño, en el año de 1793, que acarreó un proceso penal tanto al traductor como al impresor ${ }^{15}$.

Los años comprendidos entre 1795 y 1809 en los que cobró mayor dinamismo la Ilustración en la Nueva Granada con el establecimiento de la Expedición Botánica, la venida de Alexander von Humboldt y Bondpland, constituyeron la tercera revolución. La idea de que la Ilustración fue un hecho secreto y poco apoyado por la corona española reforzaba su imagen de que era oscurantista y poco amigable con sus súbditos americanos, a la vez que contrastaba con la imagen de los precursores ilustrados, intentando por todos los medios acceder al conocimiento, aun en contravía de las autoridades virreinales, inconformes con el régimen colonial, dispuestos a no "pasar su vida en la tristísima condición de súbditos coloniales"16. Los ilustrados prepararon el camino al pensamiento libertario, que se concretó el 10 de agosto de 1809 en Quito, con el establecimiento de una Junta Suprema que gobernaría en nombre de Fernando VII, desconociendo la administración de facto ${ }^{17}$.

Los eventos en Quito llevaron a que el 9 de septiembre del mismo año se reuniera, en Bogotá, un cabildo. Allí, y como último hecho, Camilo Torres leyó la "Representación del Cabildo de Bogotá capital del Nuevo Reino de Granada a la Suprema Junta Real de España”, conocido en la historiografía colombiana como "Memorial de Agravios", donde el autor criticó al régimen colonial y la discriminación de los españoles peninsulares contra los españoles nacidos en América, sin que aún se planteara la independencia ${ }^{18}$.

La última revolución en esta cadena fue la del 20 de julio de 1810 , cuando el famoso acontecimiento del florero de Llorente derivó en un Cabildo

\footnotetext{
13 John Leddy Phelan, El pueblo y el rey. La revolución comunera de 1781, Bogotá, Universidad del Rosario, 2009.

${ }^{14}$ F. V. [Florentino Vezga], op. cit., p. 883.

15 Biblioteca Nacional de Colombia, La impresión de los Derechos del Hombre. En Biblioteca Nacional. Recuperado de http://registrounico.bibliotecanacional.gov.co/content/antonio-narinola-impresion-de-los-derechos-del-hombre. Sobre la Ilustración en la Nueva Granada Renán Silva, Los ilustrados de la Nueva Granada 1760-1808. Genealogía de una comunidad de interpretación, Medellín, Fondo Editorial Universidad EAFIT, 2002.

16 F. V. [Florentino Vezga], op. cit., p. 884.

17 Jaime E. Rodríguez O., Los orígenes de la Revolución en Quito en 1809, "Procesos, Revista Ecuatoriana de Historia”, Segundo Semestre (2001), pp. 91-123. Recuperado de http://repositorio. uasb.edu.ec/bitstream/10644/3094/1/05-DE-Rodr\%C3\%ADguez.pdf.

18 El documento puede consultarse en: Camilo Torres, Representación del Cabildo de Bogotá capital del Nuevo Reino de granada a la Suprema Junta Real de España, 1809. Recuperado de http:// banrepcultural.org/bicentenario/documentos/memorial_de_agravios.pdf.
} 
revolucionario que proclamó "nuestra emancipación del poder español y el establecimiento de un orden político republicano, libre y federal" 19 .

En esta sucesión de hechos expuestos en el artículo "Nuestra revolución", encadenados de manera causal -esto es, con antecedentes y consecuentes en una narración teleológica, ascendente y progresiva, que desde el principio presagiaba el porvenir-, destacaba la noción de revolución que provocaba un cambio radical y vertiginoso en la sociedad. No se puede afirmar que el artículo de Vezga haya sido escrito deliberadamente para legitimar la llegada del liberalismo al poder; lo que sí se puede decir es que es una interpretación que privilegiaba tópicos de cuño liberal, como la noción de revolución, la de pueblo como agente de cambio y la transformación, la de ascenso moral y social con la república, el federalismo como principio organizativo validado por los precursores de la patria y la Ilustración como portadora de la luz, contraria a la ignorancia oprobiosa impuesta por la Corona española en América. Entre revolución, libertad, pueblo e ilustración se afirmaba el 20 de julio como el día de la proclamación de un "orden político republicano, libre y federal" 20 . Así se prolongaban los ideales federalistas a las luchas de los precursores de la república.

Esa defensa de la revolución y el federalismo, unida a la figuración del pasado español como un lastre de ignorancia y oscuridad, desataron en Caro el malestar que se incubó con el anuncio de los festejos del 20 de julio. En esa misma fecha, Caro publicó un artículo titulado "Non Verbo, Sed Opere", para recordar a los lectores que más que elevar arcos triunfales, era necesario recordar que los próceres de la independencia quisieron que "construyéramos una república católica y no una atea y perseguidora de la Iglesia", y que no se honraba su memoria si no se reparaban las injusticias cometidas para con ella. La Iglesia católica era, según Caro, la base que unía a la república en sus orígenes con la época en la que escribía, fundamento común que hermanaba el pasado con el presente y que definía la vida política e institucional de la república ${ }^{21}$.

\section{La pugna por la celebración del 20 de julio}

Unos días antes del artículo que señalamos en los párrafos anteriores, Miguel Antonio Caro escribió, en El Tradicionista, "Fiesta Nacional", un manifiesto de su disgusto por el festejo del 20 de julio, día de la independencia. No entendía por qué se rememoraba esa fecha "con más pompa y esplendidez

\footnotetext{
${ }^{19}$ F. V. [Florentino Vezga], op. cit., p. 884.

${ }_{20}$ Ídem.

${ }^{21}$ Miguel Antonio Caro, Non Verbo, Sed Opere, "El Tradicionista”, año I, Trim. 3, 59 (20 de julio de 1872), p. 344.
} 
que en años anteriores"22, e insinuaba una agria postura contra el agasajo, no por la fecha en sí, sino porque en él veía una amenaza contra la religión y el orden.

Para Caro, la fiesta, con su procesión de carros alegóricos, sería "un remedo de la procesión del corpus"; sarcásticamente aludía a la participación de niños disfrazados como héroes de la patria: "un Bolívar niño con barbas postizas y espada de lata sería una figura triste y mal vista". Más urgente que la pompa festiva, era que el Gobierno brindara ayuda económica a las familias descendientes de los próceres, cercanas al Partido Conservador, "proscritas del seno mismo de la patria, vilipendiadas con el título de godas" $"$. Con este artículo, Caro declaraba su posición sobre la interpretación del pasado que, a sus ojos, los liberales radicales imponían con un sesgo populachero, anticatólico y peligroso para el mantenimiento del orden y la tradición, aspectos que, según su pensamiento, eran vitales para la subsistencia de las sociedades.

Tres días después de la fiesta, Caro escribió en El Tradicionista un recuento de lo ocurrido. Decía que a pesar de haber sido un espectáculo "recargado y relumbrante", logró aglutinar alegremente a la población y sustituir "por cualquier cosa civilizada, las corridas de toros y la bulla carnavalesca con que se acostumbra dar solaz al pueblo", y remató su concepto con un cuestionamiento que, al mejor estilo de su pluma, desvirtúo el sentido de la fecha y de la común celebración: “¿El 20 de julio es en efecto aniversario de la Independencia” y respondía inmediatamente: "creemos que el 20 de julio es simplemente el aniversario de 1810 " 24 , una fecha importante porque se sentaron las bases de la independencia, pero ese día lo que pasó fue que se ratificó, según él, la dependencia a España y la fidelidad al monarca Fernando VII.

La disquisición tuvo varios puntos: el primero es que la Junta de Santafé (organizada según el modelo de la de Sevilla, que luego pasó a Cádiz) no proclamó la independencia, sino la dependencia del rey Fernando VII. La prueba era que el 14 de octubre de ese mismo año de 1810 había celebrado el cumpleaños del monarca con gran alborozo. También el que no se hubiese fraguado un partido "independentista", ya que, según Caro, muchos de los que firmaron el acta del 20 de julio abrazaron esa causa, mientras otros, una vez se desató la guerra, se alinderaron con los realistas, y muchos emigraron, fueron desterrados o pasados por armas. En consecuencia, no había algo así como una afiliación ideológica clara entre esos firmantes, un "partido por la independencia". Al final del artículo afirmaba que "verdaderamente se declaró la Independencia por el Congreso de Cundinamarca fue el 16 de julio de $1813^{\prime 25}$.

${ }^{22}$ M. A. Caro, Fiesta Nacional, "El Tradicionista”, año I, Trim. 3, 55 (11 de julio de 1872), p. 328.

${ }^{23}$ Ídem.

${ }^{24}$ M. A. Caro, El 20 de Julio, "El Tradicionista”, año I, Trim. 1, 60, (23 de julio de 1872), p. 347.

${ }^{25}$ Ibid., p. 348. 
La oposición de Caro iba más allá del simple festejo: era consciente del poder que tenía la configuración del relato del pasado como modelador de las costumbres y que en la seguidilla de eventos y personajes, lineales, cronológicos y emotivos, se perfilaban ideales políticos, se legitimaban proyectos de país, y se abría un camino que de la mano de héroes y epopeyas perfilaba los paradigmas políticos y morales a seguir.

A esta invectiva respondió José María Quijano el 31 de julio de 1872 en La América, con un artículo que exponía las inexactitudes con las que Caro negaba lo que "han reconocido tres generaciones", destruyendo de paso el pedestal construido a los padres de la patria al negarles la proclamación de la independencia y endilgarles "hacer más fuerte el lazo que nos ligaba a la metrópoli" ${ }^{26}$. La celebración del 20 de julio era, en lenguaje de Quijano Otero, una fiesta nacional en la que tenían representación todos los héroes, todas las glorias y todos los esfuerzos. Ir en contravía era desconocer un hecho que unía al pueblo, "personaje" clave en la interpretación de Quijano Otero, quien, a diferencia de Caro, avalaba la idea de "revolución popular" movida por una justa causa. Caro, por su parte, veía en nociones como "revolución" y "pueblo" un peligro que atentaba contra la tradición y el orden. Dado lo cual, su idea de independencia estaba más del lado de la diplomacia ilustrada, que de la de insurrección alborotada de un pueblo sedicioso.

Ante las tesis esgrimidas por Caro, su antagonista blasonó su autoridad histórica como aficionado a esta clase de estudios. Empezó por confirmar la relación del movimiento de 1810 con el de los comuneros (haciendo la salvedad de que este nunca pretendió romper los lazos con España) y revalidó el nexo entre la publicación de los Derechos del Hombre y el ideario de los "ilustres varones que compusieron el cabildo abierto de 1810". Para contradecir el argumento de su contrincante sobre la adhesión de la Junta de Bogotá al rey Fernando VII, afirmó que ese nombre era "una pantalla y, el sostenimiento de sus derechos, arma poderosa para romper el yugo" ${ }^{27}$, y que en el Suplemento Aviso Público, redactado por Camilo Torres, había encontrado una nota sobre los festejos del 14 de octubre de 1810, tratándose de un desagravio y no de una celebración.

Desde sus inicios, la Junta de Santafé se adhirió a la independencia. Según Quijano Otero, esto podría comprobarse en el Acta misma, según él, alterada en aquellas partes donde se refería al sostenimiento del monarca español con palabras escritas por el mismo secretario patriota; "pero la tinta no es la misma con que se ha escrito todo el documento"; es decir, que el documento había sido alterado hacia 1816 (época de la Reconquista española de las colonias), con el objeto de proteger a los patriotas del cadalso que les auguraba su disidencia de

${ }^{26}$ José María Quijano Otero, El 20 de Julio, “La América”, año 1, Trim. 1, 4 (31 de julio de 1872), p. 13.

27 J. M Quijano Otero, El 20 de Julio, “La América”, año 1, Trim. 1, 11 (24 de agosto de 1872), p. 43. 
la Corona. Quijano aseguraba: "existen pruebas de que no fue sino en 1816" cuando los pacificadores llegaron a Santafé, que se adicionaron las palabras referidas a la fidelidad a la Corona, "queriendo así minorar los cargos que habían de hacer a los vocales que firmaron el inmortal documento" 28 .

Al tiempo que los periódicos alababan la belleza de los festejos, Caro preparaba sus descargos contra la interpretación del 20 de julio que se imponía, en el artículo titulado "Historia novelesca o mentiras históricas" 29 . Con este oxímoron, Caro indicaba las contradicciones y falacias de "Nuestra revolución", un artículo que se preciaba de narrar fielmente la historia, pero que en realidad había tergiversado engañosamente los hechos.

Caro empezó diciendo que al leer el nombre de "Nuestra revolución" había creído que se trataba de la revolución liberal de 1860 y no la de 1810 , "obra de patriotas, católicos, apostólicos y romanos". Enseguida pasó a refutar los tópicos del artículo con las siguientes declaraciones:

1. Los comuneros no fueron los “primeros héroes de la libertad". Si el argumento de ir contra la autoridad fuese el criterio para heroizar, entonces, decía Caro, "tendría que subir el Diario á otros liberales anteriores a los comuneros", como Alvaro de Oyón o Lope de Aguirre que también se sublevaron. Agregaba que los reclamos no tuvieron color político, y que José Antonio Galán, uno de los líderes del movimiento, separado de los comuneros y reacio a aceptar las capitulaciones, se dedicó a andar "en guerrilla por multitud de lugares", saqueando y arruinando a los vecinos hasta convertirse en el terror de las poblaciones. Ellas, armadas para defenderse de sus desmanes, lo apresaron y entregaron a las autoridades. Caro se apoyó en José Manuel Restrepo y en José Antonio de Plaza, dos autoridades en materia histórica en el país. La mención a un historiador de cuño liberal como J. A. de Plaza, "a pesar de su odio contra el gobierno español", fungía como un argumento de autoridad que, desde la mirada histórica liberal, contradecía la interpretación defendida por el liberalismo radical. Esta réplica se define mejor en una frase: "el levantamiento contra la autoridad no hace próceres", y en ella se hace explícito la contrariedad que producía en Caro la idea de levantamiento popular, ya que se negó a llamarlo "revolución" 30 .

2. La falta de ilustración que padecían las colonias por la carencia de periódicos, la ausencia de incentivos para el estudio, era también una mentira. La reforma de estudios de Moreno y Escandón, la llegada de José Celestino Mutis en 1760, la formación de la Biblioteca pública, años antes del levantamiento comunero, demostraban que había un movimiento intelectual del que participaron algunos "ilustrados", que protagonizaron los hechos del 20 de julio. Como prueba de su argumento, Caro citó documentos publicados en periódicos sostenidos por el

28 J.M. Quijano Otero, op. cit., (31 de julio de 1872), p. 13.

${ }^{29}$ M. A. Caro, Historia novelesca o mentiras históricas, "El Tradicionista", Trim. 3, 64 (1. ${ }^{\circ}$ de agosto de 1872), p. 364.

${ }^{30}$ Ídem.

Araucaria. Revista Iberoamericana de Filosofía, Política y Humanidades, año 19, n 38. Segundo semestre de 2017. Pp. 445-466. ISSN 1575-6823 e-ISSN 2340-2199 doi: 10.12795/araucaria.2017.i38.20 
Gobierno liberal como "las Memorias de los Virreyes publicadas en los Anales de la Universidad [Nacional]", institución fundada en 1864 por los liberales radicales, de manera que Caro mantenía su estrategia de hacer uso de fuentes liberales para debilitar la interpretación liberal de la historia y fortalecer la visión conservadora.

La declaración de los Derechos del Hombre en 1794 no había sido el resultado de una conjura secreta. Antonio Nariño, el traductor, participaba de la Tertulia Eutropélica, pública y conocida; hacia parte de asociaciones literarias protegidas por el virrey José Manuel de Ezpeleta. Según Caro, era falso que el país, en aquella época, estuviera en "el estado de embrutecimiento que lo pinta el Diario" ${ }^{31}$.

En resumen, Caro hacía una crítica tenaz contra lo que llamaba una "escuela de mentiras históricas incorporada a la Universidad cuyos cursantes, unos llevados por un espíritu pueril todo lo quería convertir en novela o poesía" ${ }^{\prime 32}$. Para ellos, no era importante la defensa de la verdad ni la fidelidad de los hechos. Según Caro, el objeto de dicha escuela era el arrebatamiento y la pasión que tanto atraía al populacho; además, desviaba la verdad y tergiversaba los acontecimientos, ensalzando a los malvados y postrando a los buenos. Tampoco se medían con el mismo rasero las acciones, pues mientras se hablaba de que a Galán y a sus seguidores los guiaba un objeto político, cuando se referirían a levantamientos de poblaciones conservadoras, la misma escuela los tildaba de ladrones y bandidos. En la mente de Caro, los textos históricos escritos por los liberales habían sido hechos para mantenerlos en el poder y favorecer sus deseos revolucionarios y populacheros, y no para enseñar la verdad histórica.

M. A. Caro atendía a temas relevantes en la época: el papel modulador de las ideologías políticas en la construcción de una narrativa patria, el problema de la narración histórica y de cómo ella podría variar de acuerdo con la selección de hitos fundacionales importantes, no por el pasado en sí, sino por lo que ellos podrían significar en ese presente de 1870.

Para Caro y Quijano Otero, la historia patria, con su corolario de héroes, fechas y acontecimientos, eran fundamentales para fijar las bases culturales que, apoyadas en el pasado, ayudaran a consolidar la imagen de la república, la figuración de las tendencias políticas y las tipologías heroicas que habrían de servir como modeladores de la ciudadanía e inspirar un deber ser cívico y político.

Caro intentaba no solo demostrar los yerros históricos contenidos por el Diario de Cundinamarca, que justificaba la celebración del 20 de julio. Su ataque espoleaba la enseñanza de la historia patria que se impartía en la Facultad de Filosofía de la Universidad Nacional, con la dirección de José María Quijano. En su concepto, la manera de abordar el pasado patrio desfiguraba los hechos y sembraba errores con el fin de beneficiar el régimen federal y el liberalismo.

31 Ídem.

32 Ídem. 
El debate evidencia una postura reacia al Partido Liberal, a las reformas propuestas, a las medidas de laicización y al espíritu modernizante que seguía los modelos inglés y francés, y que desestimaba la tradición hispánica ${ }^{33}$. Para Caro, el liberalismo se remontaba a hombres como Antonio Páez y Francisco de Paula Santander, promotores de logias y protectores de sofistas; "de allí vienen Bentham, y Tracy", fundamentos de "la política anticristiana y la filosofía materialista", que instituyó en Rionegro "un sistema político y social opuesto en todo a la ciudad católica cuyos cimientos arrojaron los hombres de $1810^{\prime 34}$.

Distinta a la interpretación liberal que veía en la historia la progresión del espíritu humano reflejado en los ideales republicanos, Caro, entre otros, creía que la sociedad iba en decadencia, y que solo la defensa de la religión, la preservación de la herencia hispánica y el mantenimiento de la tradición podrían protegerla del caos.

La lectura de Quijano, más moderada, igualmente correspondía a su tiempo. Este explicaba que la fecha en cuestión no era la de un Estado ni la de un partido; era la fiesta de todos. Así, el Gobierno se habría hecho intérprete del sentimiento público para la celebración de la independencia. A diferencia de su adversario, Quijano defendía la idea de revolución como el resultado de la opresión y la injusticia que obliga a un "pueblo a apelar a la fuerza para reclamar sus derechos vulnerados" ${ }^{\prime 3}$. En tanto el motín no necesitaba para formarse más que un hecho, la revolución requería de "una idea que la haga brotar" después de un largo período de incubación y de lucha.

Esta reivindicación permitía dilucidar el movimiento del 20 de julio como una revolución benigna, que liberaba a la patria de "la garra sangrienta que la oprimía y amordazaba", sin romper, eso sí, con las tradiciones religiosas y culturales heredadas de España. Con este argumento acentuaba la libertad como una conquista que aseguraba la mejoría moral y política de la sociedad. Para demostrar su filiación conservadora, se despedía de sus lectores anunciándoles una serie de artículos sobre el programa del Partido Conservador "tal como lo entendemos y profesamos" ${ }^{\prime \prime}$.

La unificación conmemorativa del 20 de julio se reglamentó con la Ley 60 de 1873, que lo proclamó Día de la Independencia. En 1907, la Ley 39 del 15 de junio la elevó a la categoría de celebración nacional, para fortalecer la resquebrajada unidad y arraigar unos hitos históricos comunes que ayudaran a solidificar un sentimiento nacional ${ }^{37}$.

\footnotetext{
${ }^{33}$ Iván Vicente Padilla Chasing, El debate de la hispanidad en Colombia en el siglo XIX, Bogotá, Universidad Nacional, 2008.

${ }^{34}$ M. A. Caro, El 20 de Julio, “El Tradicionista”, año I, Trim. 4, 68, (10 de agosto de 1872), p. 381. Caro se refería a la Constitución liberal de Rionegro, firmada en 1863, y cuya columna vertebral fue la secularización del país y el fortalecimiento de las instituciones políticas frente a la Iglesia católica.

35 J. M. Quijano Otero, El 20 de Julio, “La América”, año 1, Trim. 1, 8 (14 de agosto de 1872), p. 29.

${ }^{36}$ J. M. Quijano Otero, El 20 de Julio, “La América”, año 1, Trim. 1, 10 (21 de agosto de 1874), p. 37.

37 Colombia, Asamblea Nacional Constituyente y Legislativa, 15 de junio: 100 años de la Ley
} 
La historia patria tejía la vida cultural y política del país; era centro de atención y control de la élite letrada; un campo de discusión de la incipiente opinión pública del país y un tema de discusión permanente en los periódicos, en los discursos, en hojas sueltas y folletines. El interés generalizado puede ser explicado parcialmente porque la historia era uno de los aspectos que debía conocer el hombre de letras, pero también porque el conocimiento histórico estaba en la base de la vida política, ayudaba en la comprensión de los fenómenos sociales acaecidos y tenía fines legitimadores para la república como el mejor de los mundos posibles.

\section{A modo de conclusión. Historia patria: actualidad y actualización del pasado}

Varias razones tenemos para presumir extrañeza frente a la polémica en cuestión. La historia patria parece caduca y poco relevante, y el relato que se consolidó con tanta pasión entre finales del siglo XIX y primeras décadas del XX, hoy parece ampuloso e incomprensible. Es un saber anacrónico y vacío, extinguido de la vida cultural colombiana, abolido del pénsum escolar hace casi 30 años. La historia, en ninguna de sus vertientes, hace parte de la formación académica de las jóvenes generaciones, quienes ignoran por completo el pasado, y con relación a Colombia, carecen de los elementos mínimos para la comprensión del presente. Las fechas y los acontecimientos que organizaron la historia patria durante varias generaciones hoy carecen de significado; su lenguaje resulta incomprensible y los hechos narrados son considerados irrelevantes, no porque en sí lo sean, sino porque fueron hechos para otra sociedad.

Otra razón del descrédito que sufrieron la historia patria y los textos usados hasta entonces en el país puede encontrarse en la llamada batalla de los manuales $^{38}$, nombre que recibió la discusión que a mediados de los años ochenta del siglo XX involucró a la primera generación profesional de historiadores del país (educados en el rigor científico de las universidades) y a la Academia Colombiana de Historia ${ }^{39}$ (cuyos miembros aficionados al trabajo histórico eran

del Centenario, Ley 30 de 1907, del 15 de junio, por la cual se ordena solemnemente la celebración del centenario de la Independencia nacional, 2010. Recuperado de http://albicentenario.com/index archivos/Page1869.htm.

${ }^{38}$ Germán Colmenares, La batalla de los manuales en Colombia [en Michel Reikenberg, comp.: Latinoamérica: enseñanza de la historia, libros de texto y conciencia histórica, Buenos Aires, Flacso, Georg Eckert Instituts, 1991], pp. 122-134.

${ }^{39}$ Sobre la primera fase de la polémica véase: Sol Alejandra Calderón Patiño, Las representaciones de la nación en los manuales de historia de Colombia (1984-1986) [en Alvaro Acevedo Tarazona y Gabriel Samacá Alonso, Manuales escolares y construcción de nación en Colombia: siglos XIX y XX, Bucaramanga, Universidad Industrial de Santander, 2013], pp. 238-242. 
partidarios de las apologías sobre el pasado de los grandes hombres y las gestas heroicas). Fundada en 1905, la Academia fue desde entonces el órgano consultor en materia de enseñanza histórica y de formación de textos escolares ${ }^{40}$.

Desde la segunda mitad del siglo XIX, la historia fue un saber central para la consolidación de la patria y la construcción nacional. El conocimiento del pasado ayudaba a la creación de referentes comunes, a la vinculación emotiva de los habitantes más allá del terruño y a la concepción de una experiencia histórica compartida de la que hacían parte los antepasados, los coetáneos y las generaciones futuras. La historia permitía que unas nociones abstractas como patria, nación o soberanía adquirieran, a través de las gestas, la sangre derramada y los caídos en la lucha, una concreción ejemplarizante que llenaba a los corazones de orgullo y del deseo de emular, si fuese necesario, a los héroes de cuyo martirio había brotado la libertad.

$\mathrm{Su}$ creciente importancia puede verse en las diversas iniciativas que surgieron en el país desde finales de la década de los sesenta: publicación de libros, artículos de prensa, documentos históricos también en periódicos (el periódicos y en libros), los primeros intentos de organización del archivo y del Museo Nacional (el primero por cuenta de José María Vergara y Vergara y el segundo por José María Quijano O.) ${ }^{41}$, la existencia de colecciones documentales que fueron cedidas o vendidas a la Biblioteca Nacional, etc. Todos ellos son indicadores del interés por organizar y formalizar el ramo de la historia patria, y con ella afianzar una propedéutica cívica para la creación de responsabilidades políticas con el Estado, el territorio y los conciudadanos.

La producción de libros de historia patria pensados para los fines educativos fue, en parte, una respuesta a la necesidad de atemperar los ánimos de los grupos políticos enfrentados, pero también una iniciativa que buscaba una comprensión común del pasado, que como buen maestro enseñara los vicios y las virtudes con sus correspondientes sanciones y premios. De hecho, en 1870 se firmó el primer contrato por la escritura de un libro de historia patria entre el Gobierno y José María Quijano, destinado a la enseñanza en las escuelas y colegios del país ${ }^{42}$.

${ }^{40}$ Hans-Joachim König, Los caballeros andantes del patriotismo [en Michel Reikenberg, comp.: Latinoamérica: enseñanza de la historia, libros de texto y conciencia histórica, Buenos Aires, Flacso, Georg Eckert Instituts, 1991], pp. 122-134.

${ }^{41}$ En la Memoria de la Secretaría de lo Interior del año 1868 se consignaron los informes del archivero y bibliotecario nacional. El archivero recordaba que antes de 1867, "los archivos nacionales habían estado diseminados en diversas oficinas, cada uno a cargo de un archivero particular, todos ellos estaban colocados en lugares húmedos que los deterioraban" (p. iv). El bibliotecario decía que "carecía de documentos; sólo podía contar con tradiciones más o menos incompletas" (p. v). Biblioteca Nacional de Colombia (BNC), Fondo Vergara, pieza 4, "Memoria del Secretario de lo Interior y relaciones esteriores al Congreso Nacional de 1869”, Bogotá, Imprenta de El Liberal, 1869.

42 Archivo General de la Nación (AGN), Sección: República; Fondo Ministerio de lo Interior y Relaciones Exteriores, Tomo 5, Folio: 126-128, "Factura por la entrega de diez pliegos impresos del compendio de Historia patria en la dirección de Instrucción Pública, conforme al contrato de 14 del presente que reforma el de 6 de noviembre de 1872", Bogotá, 16 de septiembre de 1874.

Araucaria. Revista Iberoamericana de Filosofía, Política y Humanidades, año 19, n 38. Segundo semestre de 2017. Pp. 445-466. ISSN 1575-6823 e-ISSN 2340-2199 doi: 10.12795/araucaria.2017.i38.20 
La existencia de una narración en la que primaba la matriz épica, ayudaba a monumentalizar hechos y personajes, a fin de fortalecer no solo una especie de culto cívico que enfatizaba la adscripción y la fidelidad de los ciudadanos al Estado, sino también la voluntad de mantenerse culturalmente unidos. La ordenación de un relato estereotipado, sin mayor detalle en términos de los procesos, en el que buenos y malos estaban rotundamente diferenciados, y sus acciones y personalidades coincidían con modelos morales encarnados en el uso de adjetivos como "Bolívar el libertador" y "Sámano el sanguinario", ayudaba a solidificar la vida comunitaria en una forma de organización política relativamente inédita como la república ${ }^{43}$.

Cuando decimos que la historia patria es un relato que intentaba ser consensuado sobre los ideales de la patria representados en sus héroes y en sus acciones, no afirmamos que haya sido neutral o carente de ideología; es evidente, en la polémica que hemos trabajado, que la ideología estaba presente y era un asunto de confrontación.

Denunciar las posibles trampas doctrinales de la historia sería reducir el problema a la enunciación del relato y dejar de lado las motivaciones históricas que ayudaron en su definición. El reto es proponer un análisis crítico de la historia, una mirada historiográfica que ahonde en sus disposiciones, en la definición del pasado y en las condiciones, necesidades, usos; es reconocer que la historia tiene una historia, que es una disciplina que se modifica y se construye permanentemente en relación con el presente.

Entender la orientación ideológica de una versión del pasado nos ayuda a comprender el pasado mismo y las condiciones ontológicas y deontológicas que perfilan a una época y a una sociedad. Y cuando intentamos abordar esta problemática en un punto definido de nuestra historia, buscamos mostrar el nivel de actualidad que tenía el pasado para aquella. No en vano, a partir de 1870, se pueden identificar una serie de acciones concretas, en procura de establecer unos criterios mínimos, no solo producidos por el capricho de un autor, sino que retomaron las versiones existentes hasta la época, compendiadas, resumidas y presentadas en lenguaje sencillo.

El debate que hemos presentado deber ser visto no solo como una polémica acerca del pasado, sino también como un duelo que puso en evidencia la importancia de la historia en los derroteros que socialmente se trazaban; de qué manera las interpretaciones respondían también a una idea de sociedad: de cambios o permanencias, revolucionaria o tradicionalista, pero, en todo caso, adherida a la república.

La emergencia de la historia patria como un relato y un saber en proceso de formalización coincidió con la importancia que el conocimiento del pasado

${ }^{43}$ Cfr. Rodolfo de Roux López, La insolente longevidad del héroe patrio, Caravelle, 72(1) (1999), pp. 33-43. Recuperado de http://www.persee.fr/doc/carav_1147-6753_1999_num_72_1_2832. 
tenía en la vida pública, con su pertinencia social como problema actual, en la medida en que ayudaba a explicar el presente y a pensar el porvenir. Si se miran las publicaciones históricas que se regularizaron durante ese período, la inquietud de los legisladores y de los escritores era que efectivamente los textos históricos fueran comprensibles, sencillos y claros para los lectores, sin que por ello perdieran el carácter "serio" y dramático. El pasado debía ser legible o, en términos de Paul Ricoeur, refigurado ${ }^{44}$, lo que significa que los textos que se ponen a disposición de los lectores o del auditorio, tienen que estar presentados en las coordenadas narrativas, metafóricas, lingüísticas y editoriales de la época, de modo que se garantice no solo la legibilidad, sino los posibles usos y sentidos.

Dicha preocupación por la legibilidad del pasado, por dotarlo de una actualidad que lo hiciera comprensible, necesario y útil, fue en parte el proceso que se vivió durante esta época. La definición de festejos, la promoción de textos escolares que utilizando narrativas y formatos conocidos pudieran llegar a todos los públicos, la paulatina definición de los contenidos históricos a enseñar, la publicación de documentos antiguos, así como la divulgación en periódicos, hojas sueltas, folletos y "revistas" de artículos históricos son indicadores sobre la importancia del pasado y su actualidad como tema central en las discusiones políticas y sociales de la segunda mitad del siglo XIX en Colombia.

\footnotetext{
${ }^{44}$ Paul Ricoeur, Tiempo y narración. Tomo III, El tiempo narrado, México, Siglo XXI editores, 1996.
} 


\section{Referencias bibliográficas:}

Archivo General de la Nación (AGN), Sección: República; Fondo Ministerio de lo Interior y Relaciones Exteriores, Tomo 5, Folio: 126-128, "Factura por la entrega de diez pliegos impresos del compendio de Historia patria en la dirección de Instrucción Pública, conforme al contrato de 14 del presente que reforma el de 6 de noviembre de 1872", Bogotá, 16 de septiembre de 1874.

Biblioteca Nacional de Colombia (BNC), Fondo Vergara, pieza 4, "Memoria del Secretario de lo Interior y relaciones esteriores al Congreso Nacional de 1869", Bogotá, Imprenta de El Liberal, 1869.

Biblioteca Nacional de Colombia (BNC), La impresión de los Derechos del Hombre. Biblioteca Nacional, sitio web. Recuperado de http:// registrounico.bibliotecanacional.gov.co/content/antonio-narino-laimpresion-de-los-derechos-del-hombre

Borda, José Joaquín, El gran día, “El Mosaico”, Trim. 2, 25 (1871), p. 185.

Borda, J. J., La gran semana de Bogotá, “El Mosaico”, Trim. 3. ${ }^{\circ}, 30$ (1859), p. 338.

Calderón Patiño, Sol Alejandra, ¿Tóxicas o innovadoras? Las representaciones de la nación en los manuales de historia de Colombia (1984-1986). En Alvaro Acevedo Tarazona y Gabriel Samacá Alonso, Manuales escolares y construcción de nación en Colombia: siglos XIX y XX, Bucaramanga, Universidad Industrial de Santander, 2013, pp. 238-242.

Cardona Z., Patricia, Memoria, palabra y acción. La historia patria un saber para el sentimiento, "Anuario Colombiano de Historia regional y de las fronteras", 21(2) (2016). Recuperado de http://revistas.uis.edu.co/index. php/anuariohistoria/article/view/5540

Cardona Z., Patricia, Trincheras de tinta, Medellín, Fondo Editorial Universidad EAFIT, 2016.

Caro, M. Antonio, El 20 de Julio, "El Tradicionista", año I, Trim. 1, 60, (23 de julio de 1872), p. 347.

Caro, M. A., El 20 de Julio, "El Tradicionista", año I, Trim. 4, 68, (10 de agosto de 1872), p. 381.

Caro, M. A., Fiesta Nacional, "El Tradicionista”, año I, Trim. 3, 55 (11 de julio de 1872), p. 328.

Caro, M. A., Historia novelesca o mentiras históricas, "El Tradicionista", Trim. 3, 64 (1. ${ }^{\circ}$ de agosto de 1872), p. 364.

Caro, M. A., Non Verbo, Sed Opere, "El Tradicionista", año I, Trim. 3, 59 (20 de julio de 1872), p. 344.

Chartier, Roger, Cuatro preguntas a Hayden White, "Historia y Grafia", 3 (1994), pp. 231-246. 
Colmenares, Germán, La batalla de los manuales en Colombia. En Michel Reikenberg, comp.: Latinoamérica: enseñanza de la historia, libros de texto y conciencia histórica, Buenos Aires, Flacso, Georg Eckert Instituts, 1991, pp. 122-134.

Colmenares, G. Los partidos politicos en Colombia y las clases sociales, Medellín, La Carreta, 2009.

Colombia, Asamblea Nacional Constituyente y Legislativa, 15 de junio: 100 años de la Ley del Centenario, Ley 30 de 1907, del 15 de junio, por la cual se ordena solemnemente la celebración del centario de la Independencia nacional, 2010. Recuperado de http://albicentenario.com/index_archivos/ Page1869.htm.

Cordovez Moure, José María, El 20 de julio de 1872. En Reminiscencias de Bogotá. Recuperado de http://www.banrepcultural.org/blaavirtual/ historia/remini/remini10.htm

Croix, Luis Perú de la, Diario de Bucaramanga, Caracas, Ministerio Popular para la Comunicación y la Información, 2009, p. 185.

F. V. [Florentino Vezga], Nuestra revolución, "Diario de Cundinamarca", Bogotá, año III, 773 (19 de julio de 1872), pp. 883-884.

Gómez Hermosilla, José M., Arte de hablar en prosa y en verso, tomo 2 , Madrid, Imprenta real, 1826, pp. 57-87.

González, Marcos, Ceremoniales, fiestas y nación. Bogotá: un escenario de los estandartes muiscas al himno nacional, Bogotá, Intercultura, 2012.

Hartog, François, Creer en la Historia, Chile, Ediciones Universidad Finis Terrae, 2014.

König, Hans-Joachim, Los caballeros andantes del patriotismo. En Michel Reikenberg, comp.: Latinoamérica: enseñanza de la historia, libros de texto y conciencia histórica, Buenos Aires, Flacso, Georg Eckert Instituts, 1991, pp. 122-134.

Padilla Chasing, Iván Vicente, El debate de la hispanidad en Colombia en el siglo XIX, Bogotá, Universidad Nacional, 2008.

Phelan, John Leddy, El pueblo y el rey. La revolución comunera de 1781, Bogotá, Universidad del Rosario, 2009.

Pomian, Krzystof, Sobre la historia, Madrid, Cátedra, 2007, p. 59.

Quijano Otero, José María, Compendio de historia patria, Bogotá, Imprenta de Medardo Rivas, 1874.

Quijano Otero, J.M., El 20 de Julio, “La América”, año 1, Trim. 1, 4 (31 de julio de 1872), p. 13.

Quijano Otero, J. M., El 20 de Julio, “La América”, año 1, Trim. 1, 11 (24 de agosto de 1872), p. 43.

Quijano Otero, J. M., El 20 de Julio, “La América”, año 1, Trim. 1, 8 (14 de agosto de 1872), p. 29. 
Quijano Otero, J. M., E1 20 de Julio, “La América”, año 1, Trim. 1, 10 (21 de agosto de 1874), p. 37.

Quijano Otero, J. M., Memoria histórica entre los Estados Unidos de Colombia i el Imperio del Brasil, Bogotá, Imprenta de Gaitán, 1869.

Restrepo, José Manuel, Historia de la revolución de Colombia en la América meridional, París, Librería Americana, 1826.

Ricoeur, Paul, Tiempo y narración. Tomo III, El tiempo narrado, México, Siglo XXI editores, 1996.

Rodríguez O., Jaime E. Los orígenes de la Revolución en Quito en 1809, "Procesos, Revista Ecuatoriana de Historia”, Segundo Semestre (2001), pp. 91-123. Recuperado de http://repositorio.uasb.edu.ec/ bitstream/10644/3094/1/05-DE-Rodr\%C3\%ADguez.pdf.

Romero, Raúl Román y Vanessa Niño de Villeros, El día de la Independencia de Colombia. La exclusión de los hechos históricos de la región caribe, 1821-1919, “Memorias”, 21 (2013). Recuperado de http://rcientificas. uninorte.edu.co/index.php/memorias/article/viewArticle/3860/5065\#n_2

Roux López, Rodolfo de, La insolente longevidad del héroe patrio, Caravelle, 72(1) (1999), pp. 33-43. Recuperado de http://www.persee.fr/doc/ carav_1147-6753_1999_num_72_1_2832

Samper, José María, Los partidos políticos en Colombia. Estudios históricopolítico, Bogotá, Imprenta de Echavarría Hermanos, 1873.

Silva, Renán, Los ilustrados de la Nueva Granada 1760-1808. Genealogía de una comunidad de interpretación, Medellín, Fondo Editorial Universidad EAFIT, 2002.

Torres, Camilo, Representación del Cabildo de Bogotá capital del Nuevo Reino de granada a la Suprema Junta Real de España, 1809. Recuperado de http:// banrepcultural.org/bicentenario/documentos/memorial_de_agravios.pdf.

Zermeño Padilla, Guillermo, Imparcialidad, objetividad y exactitud. Valores epistémicos en el origen de la Historiografía moderna en México (18401960), “Historia y Grafia”, 20 (2003), pp. 49-83. 